\title{
Impossible Modernism: T.S. Eliot, Walter Benjamin, and the Critique of Historical Reason By. Robert S. Lehman
}

Stanford UP, 2016. $\mathrm{x}+241 \mathrm{hlm}$.

\author{
Jeffrey Willever Jacobson \\ Universitas Gadjah Mada
}

Zaman sekarang, manusia akademik barangkali sudah terbiasa menganggap dirinya sendiri sebagai manusia pascamodern, atau bahkan pasca-pascamodern. Pemilihan tema isu Poetika ini menunjukkan bahwa pemikiran pascamodernis tetap relevan dalam kajian sastra dan ilmu-ilmu humaniora secara umum. Namun, bagaimanapun kita mendefinisikan yang pascamodern, definisi itu niscaya bergantung pada suatu pemahaman akan yang modern. Dengan kata lain, pertanyaan akan yang modern-baik sebagai modernisme maupun modernitas-tetap terbuka, dan sarjana-sarjana dalam ilmu humaniora tetap harus berusaha memberikan jawaban kepadanya. Beberapa tahun terakhir ini, lingkup kajian modernis (modernist studies) telah meluas dalam ruang dan waktu; sementara istilah 'modernisme' sebelumnya merujuk sekelompok penulis avant-garde di Amerika dan Eropa pada awal abad ke-20 (dan untuk alasan itu cenderung dihina atau diabaikan oleh para pascamodernawan), berkembangnya kajian modernis di awal abad ke-21 menyebabkan suatu pemahaman akan modernisme yang lebih inklusif, sehingga semakin banyak penulis yang merepresentasikan sudut pandang yang beraneka-ragam dianggap sebagai penulis modernis atau dibicarakan dengan rujukan kepada modernisme (atau bahkan modernisme-modernisme (modernisms)). Kecenderungan baru ini disebut sebagai "kajian modernis baru" (the new modernist studies) ${ }^{1}$. Sebagai salah satu contoh dari bidang sastra Indonesia, Christopher GoGwilt telah mengangkat Pramoedya Ananta Toer sebagai penulis modernis yang menggali "sampai ke akar-akar" sejarah dan pra-sejarah Indonesia (2011: 178ff)2.

Di satu sisi, Robert S. Lehman, dalam bukunya Impossible Modernism: T.S. Eliot, Walter Benjamin, and the Critique of Historical Reason (2016), memosisikan dirinya sebagai sarjana 'modernis tradisional': kedua tokoh yang dia bicarakan di sini, T.S. Eliot dan Walter Benjamin, merupakan 'raksasa' modernisme dalam artinya yang pra-abad-ke-21. T.S. Eliot adalah penyair Amerika-Inggris yang paling terkenal untuk puisinya The Waste Land dan "The Love Song of J. Alfred Prufrock". Walter Benjamin adalah pemikir Jerman yang eklektis; karyanya yang paling sering dibaca adalah eseinya yang berjudul, "Karya Seni dalam Zaman Reproduksi Mekanisnya". Lehman tidak mengangkat kedua tokoh tersebut sebagai penolakan atas kajian modernis baru; sebenarnya, kita bisa melihat dampak dari kajian baru itu dari halaman pertama (preface), ketika Lehman menyatakan bahwa bukunya mengemukakan "suatu interpretasi atas modernisme Eropa" (Lehman xiii, tekanan saya). Namun, Lehman menemukan potensi dalam pemikiran Eliot dan Benjan untuk suatu kritik atas apa yang dia anggap sebagai "titik buta" (p. xv) kajian modernis baru, yakni, historisismenya.

Historisisme yang dimaksud di sini adalah kecenderungan mengutamakan konteks historis ketika menginterpretasikan teks; apa yang penting adalah makna teks saat teks itu ditulis (dibandingkan dengan makna untuk pembaca masa kini). Salah satu implikasi dari pandangan ini adalah sejarah cenderung dilihat sebagai sekumpulan fakta empiris yang ada begitu saja. Sejarah adalah penyebab transendental yang menjelaskan apa yang ditemukan sebagai konsekuensi dirinya sendiri. Dengan kajian ini, Lehman ingin membantah historisisme itu secara khusus sebagaimana telah diandalkan dalam membaca Eliot dan Benjamin. Eliot dibaca secara umum sebagai tokoh modernis yang menghaluskan dorongan modernisme untuk selalu mencari yang baru melalui suatu kesatuan di antara inovasi formal dengan tradisi. Dari sudut pandang ini, hal yang terpenting dari puisi Eliot adalah

\footnotetext{
${ }^{1}$ Untuk suatu ulasan atas perkembangan-perkembangan ini yang lebih menyeluruh, pembaca disarankan supaya melihat Mao, Douglas dan Rebecca L. Walkowitz. "The New Modernist Studies". PMLA Jil. 123, No. 3, Mei 2008. 737-748.

${ }^{2}$ GoGwilt, Christopher. The Passage of Literature: Genealogies of Modernism in Conrad, Rhys, and Pramoedya. Oxford UP, 2011.

${ }^{3}$ (Das Kunstwerk im Zeitalter seiner technischen Reprodurierbarkeit; The Worke of Art in the Age of Mechanical Reproduction).
} 
dampak yang diberikannya kepada sastra dan ilmu sastra yang menyusulnya (p. 28f.). Lintas tulisan Benjamin dibaca secara umum sebagai mengikuti arus perkembangan sejarah intelektual Jerman yang dirangkum dalam rumusan "dari Kant ke Hegel (ke Marx)" (p. 122) ${ }^{4}$; demikian, pemikiran Benjamin dibaca sebagai konsekuensi dari sejarah yang 'mengandung'nya.

Kedua pembacaan tersebut, menurut Lehman, tidak melihat bagaimana sejarah sebenarnya diangkat dan dipermasalahkan sebagai suatu tema dalam kedua pemikir itu: "dengan hasrat mereka untuk membaca modernisme secara historis, kritikus-kritikus jarang berhenti untuk memikirkan bagaimana sejarah dibaca oleh modernisme" (p. xv) ${ }^{5}$. Justru hal itu-pembacaan modernisme Eliot dan Benjamin atas sejarahmerupakan persoalan pokok buku Lehman. Resensi saya berfokus pada aspek-aspek pembacaan Lehman atas kedua tokoh tersebut yang berkaitan dengan persoalan utama itu. Lehman menelusuri permasalahan Eliot akan sejarah melalui tiga puisinya-"The Love Song of J. Alfred Prufrock", "Gerontion", dan The Waste Land dan salah satu eseinya, "Tradition and the Individual Talent". Dalam puisi pertama dan ketiga tersebut, Lehman juga meneliti penaskahan, dan menemukan dukungan yang sangat menarik untuk tesisnya dalam bagian-bagian dari kedua puisi itu yang tidak muncul di versi terakhir yang diterbitkan. Pelacakan akan puisi-puisi ini sampai tataran naskah menyingkapkan suatu proses 'pemotongan' (terkadang juga 'amputasi'): "lelaki muda yang personal, cemas, dan khawatir telah terpotong. Hanyalah bentuk murni operasi puitis yang tersisa" (p. 39). Secara khusus, pemotongan ini terlihat dari 38 baris yang hampir Eliot tambahkan ke "Prufrock" yang menggambarkan kegilaan pembicaranya secara pribadi. Seksi itu dipotong, tetapi dua baris ikonik darinya dipertahankan (saya tidak akan mencemarinya dengan terjemahan): "I should have been a pair of ragged claws / Scuttling across the floors of silent seas" (p. 37). Menurut Lehman, citra kepiting itu, "makbluk yang menggenggam dan membentuk tanpa maksud sadar apa pun ... menandai suatu ketidakhadiran", yaitu, ketidakhadiran penyair secara pribadi, dan sekaligus "I" (p. 39)7.

Eliot membicarakan suatu proses yang serupa dengan 'pemotongan' di atas dalam eseinya, "Tradition and the Individual Talent". Supaya terus berkembang, seorang penyair harus semakin sadar akan tradisi sejarah sastra. Penghayatan akan tradisi hanya bisa terjadi melalui suatu pengorbanandiri atas kepribadian sendiri. Menurut Eliot, "manusia yang menderita" harus dipadamkan supaya "pikiran yang menciptakan" bisa muncul (p. 40) ${ }^{8}$. Penyair mengorbankan riwayat atau sejarahnya secara pribadi supaya dapat mengakses sejarah 'universal', yaitu, "keseluruhan sastra Eropa sejak Homeros" (p. 40)'. Disamping itu, Eliot juga menggambarkan proses puitis dengan suatu analogi dengan kimia: katalisis. Pikiran seorang penyair dewasa diibaratkan dengan katalis dalam reaksi kimia, sementara pengalamannya adalah zat-zat yang bereaksi dan menjadi zat baru; apa yang dihasilkan dalam reaksi ini adalah kemunculan karya seni yang benar-benar baru. Katalis harus ada supaya reaksi bisa terjadi, tetapi katalis tidak diubah dalam reaksi itu. Ada kesenjangan dalam analogi ini yang sudah banyak ditunjukkan oleh pembaca Eliot yang sebelumnya: terkadang pikiran penyair diibaratkan dengan katalis, seperti dideskripsikan di atas, dan terkadang pikirannya diibaratkan dengan medium, yaitu, tempat reaksi itu terjadi. Kesenjangan ini sering dibaca sebagai kesenjangan belaka, tetapi bagi Lehman ada kemungkinan produktif darinya: pikiran penyair sebagai suatu pembagian-diri di antara medium dan katalis yang serupa dengan 'pembagian' sebagai hasil pemotongan-diri yang sudah kita lihat di kasus Prufrock (p. 47).

Kedua gambaran atas penyair yang dibicarakan di atas-sebagai kepiting yang menggenggam dan sebagai katalis sekaligus medium-menunjukkan suatu sikap tertentu terhadap sejarah. Apa yang muncul di hadapan penyair dari sejarah bersifat terberi, given. Ketika mencipta, seorang penyair

\footnotetext{
4 "von Kant bis Hegel (bis Marx)".

5 "in their eagerness to read modernism historically, critics have rarely paused to consider how history is read by modernism".

6 "The personal, anxious, worried young man has been cut away. All the remains is a particularly pure figure of the poetic operation".

7 "a creature that grabs and shapes absent any conscious intention ... marks an absence"... "the presence of something impersonal, inbuman, but still active".

${ }^{8}$ the "man who suffers"... the"mind which creates".

9 the "whole of the literature of Europe from Homer".
} 
"bertanggung jawab atas apa yang dapat dilakukan dengan bahan yang harus diterima begitu saja" (p: 61); keadaan penyair berbeda dengan keadaan kritikus yang hanya bertanggung jawab atas apa yang dia inginkan. Ada hal-hal dari sejarah atau tradisi yang tidak dapat ditolak; namun, proses penciptaan mengubah bahan itu. Hal ini paling kelihatan dari analogi katalisis di atas: penyair tidak dapat membuang pengalamannya, tetapi dia tetap bisa menggunakannya dalam suatu reaksi yang mengubah pengalaman itu menjadi karya seni. Sejauh pengalaman itu datang begitu saja dari sejarah, proses penciptaan seni merupakan suatu konstruksi akan sejarah, bukan suatu penerimaan belaka, dan seni itu tidak ditentukan oleh sejarah sebagai penyebab melainkan didasari olehnya sebagai kondisi.

Lehman membaca The Waste Land dalam kerangka dua genre yang berada secara berbeda-beda dalam teks: satir dan mitos. Lehman mengikuti definisi satir Fredric Bogel: satir bukan pertama-tama suatu pengakuan akan perbedaan yang sudah ada sebelumnya; sebaliknya, satir lahir dari kecemasan akan kesamaan. Satir adalah "mekanisme tekstual" untuk memproduksikan perbedaan; satir pertamatama menjadikan yang lain sebagai yang lain (p. 75). Satir dalam arti ini dilihat dalam Eliot di sebagian teks yang dipotong dari versi akhirnya. Bagian ini menggunakan heroic couplet, suatu skema rima dan metris lama yang digunakan secara paling terkenal oleh Alexander Pope di abad ke-18. Bagian ini bercerita tentang kebiasaan sehari-hari seorang penyair perempuan, Fresca, dengan nada yang sangat menghina.

Fresca bercirikan proses-proses jasmani seperti konsumsi dan pembuangan air. Dia membaca secara luas tetapi tidak secara mendalam. Eliot menyiratkan bahwa puisi yang Fresca tulis bersifat enteng. Namun, kehidupan Fresca sebagaimana diceritakan di sini tidak jauh berbeda dengan perilaku penyair dewasa sebagaimana dideskripsikan oleh Eliot dalam "Prufrock" dan "Tradition"; penyair dewasa juga, sebagai kepiting dan katalis, bekerja secara otomatis. Padahal Eliot dan Fresca tidak dapat dibedakan secara praktis melalui proses kepenyairan mereka, mereka tetap dapat dibedakan secara formal, melalui adanya satir itu sendiri. Demikian Eliot melakukan suatu "pembedaan formal" (formal distinction) di antara dirinya dengan Fresca (p. 81). Lagipula, satir sendiri adalah semacam 'seni membedakan'; Fresca hanya mereproduksi tradisi secara tidak sadar, tetapi Eliot, sebagai pengguna satir, menetapkan dirinya sebagai orang yang dapat membedakan (p. 81).

Unsur satiris dalam The Waste Land terutama terdapat di bagian-bagian yang akhirnya tidak diterbitkan; Ezra Pound, yang berjasa sebagai redaktur puisi itu, mendorongnya ke arah 'mitis'. Pound menyuruh Eliot supaya menggantikan rujukan ke penulis-penulis yang agak kontemporer seperti Conrad and Dickens dengan rujukan kuno dan/atau dari luar tradisi sastra Eropa ${ }^{10}$. Penggantian rujukan ini seolah-olah menunjukkan perhatian kepada "metode mistis" (mythical method) yang diteorikan oleh Eliot sendiri dalam membaca novel Ulysses oleh James Joyce. Penulis seperti Joyce yang menggunakan metode mitis terus-menerus menenun yang kuno bersama dengan yang kekinian (p. 88).

Jejak dari metode mitis jelas ada dalam The Waste Land, tetapi menurut Lehman, 'mitos' mempunyai arti yang lebih asali bagi Eliot dalam karya itu, yakni, sebagai "pemotongan dalam naratif modernisme sastra" (p. 92) ${ }^{11}$. Jadi, di satu sisi, The Waste Land, dengan seolah-olah merangkum keseluruhan sejarah sastra, merepresentasikan sejarah itu sebagai suatu yang tertutup dan selesai; ini adalah aspek puisinya yang mengikuti metode mitis. Sementara itu, di sisi lain, The Waste Land tetap menyimpan ruang untuk mitos sebagai suatu luar mutlak dari sejarah itu. Mitos tidak mempunyai dimensi temporal. Demikian, ditulis Lehman, mitos "memberlakukan suatu visi atas sejarah yang tidak sesuai secara mutlak dengan naratif ... dari sudut pandang naratif, mitos hanya dapat dipikirkan sebagai akhir (menentu) naratif; dari sudutpandang mitos, naratif tidak dipikirkan sama sekali" (p. 108) ${ }^{12}$.

Mitos dalam arti yang diuraikan di atas dapat dibaca di salah satu seksi dalam The Waste Land.

\footnotetext{
${ }^{10}$ (misalmya, kepada para upanisad (lib. 116))

11 "an interruption of the narrative of literary modernism".

12 "myth imposes a vision of history absolutely incompatible with narrative presentation ... From the vantage of narrative, myth can only be thought as narrative's (definitive) end; from the vantage of myth, narrative is not thought at all".
} 
Berikut adalah bagian yang dikutip Lehman (sekali lagi, saya tidak berani menerjemahkannya): If there were water

And no rock

If there were rock

And also water

And water

A spring

A pool among the rock

If there were the sound of water only

Not the cicada

And dry grass singing

But sound of water over a rock

Where the hermit thrush sings in the pine trees

Drip drop drip drop drop drop drop

But there is no water (p. 115)

Mitos, direpresentasikan di sini sebagai padang gurun, adalah ranah tanpa sejarah dan tanpa naratif. Tidak ada apa-apa yang terjadi di dalamnya. Baris-baris ini sangat berbeda dengan citra-citra air yang mendominasikan bagian lain puisinya; bagi Lehman, air di sini adalah dasar untuk suatu "fekunditas banggi" (perverse fecundity) yang ditandai oleh siklus musim yang tidak henti-hentinya, mayat yang berpucuk menjadi tanaman, dan degenerasi dan pembusukan secara umum (p. 115). Air adalah ranah sejarah, naratif, dan perkembangan; keringnya padang gurun adalah ketidakadaan unsurunsur tersebut. Akhirnya, Eliot tidak mampu meninggalkan ranah mitos hanya pada dirinya sendiri dan memasukkan perubahan dalam bentuk halilintar dan hujan, ditandai oleh kekeruyuk ayam yang bagi Lehman merupakan rujukan kepada Chaucer (p. 117). Menurut Lehman, Eliot tidak berhasil memisahkan mitos dari sejarah dan naratif dalam The Waste Land. Dengan menerima ketidaksesuaian dua konsepsi mengenai waktu yang saling mengecualikan, The Waste Land, bertahan sebagai "puisi krisis dalam modernisme sastra, semacam kematian di tengah kehidupan" (p. 118) ${ }^{13}$. Sebagaimana diindikasikan di atas, salah satu tujuan Lehman adalah menolak tafsir historisis atas karir Benjamin sendiri. Menurut tafsir itu, Benjamin pertama-tama mempelajari Kant karena universitas-universitas di Jerman pada awal abad ke-20 didominasi oleh dosen neo-Kantian. Kemudian dia menolak Kant dan memilih Hegel, lalu kemudian, Marx; demikian, perkembangan pemikirannya secara pribadi berkorespondensi dengan perkembangan sejarah intelektual Jerman secara umum. Menurut Lehman, penelusuran ini hanya sepertiga betul: Benjamin memang sangat dipengaruhi oleh Marx di bagian akhir karirnya. Namun, dia tidak pernah mengikuti Hegel, dan mendeskripsikannya dalam sebuah surat sebagai "seekor binatang intelektual, seorang mistikus kekuatan mentab" (p. 124). Lebih persisnya lagi bagi Lehman, Benjamin tidak pernah menolak Kant. Benjamin memang tidak membuat kajian lagi tentang Kant sebagaimana yang pernah ia rancang untuk disertasi doktoralnya, tetapi "arus bawah tanah Kantianisme" ${ }^{14}$ (p. 123) tetap ditemukan dalam pemikiran Benjamin yang dewasa. Lagipula, Kantianisme ini sangat penting bagi kritik Benjamin sendiri atas historisisme.

Menurut pembacaan Lehman, Benjamin awal menerima kategori-kategori Kant ${ }^{15}$, tetapi hanya di ranah mereka sendiri, yaitu, sebagai dasar ilmu pengetahuan alamiah. Posisi ini berbeda dengan para neo-Kantian yang menganggap kategori-kategori, dan demikian suatu pemahaman saintistik akan

\footnotetext{
13 "remains within literary modernism a poem of crisis, a kind of death in the middle of life".

14 ("a subterranean current of Kantianism")

${ }^{15}$ Kategori dalam Kant adalah konsep a priori yang tidak bisa dideduksi secara logis melainkan harus ada secara niscaya supaya pengalaman kita sesuai dengan bagaimana kita mengalaminya, atau supaya objek-objek bisa muncul bagi kita sebagaimana mereka muncul. Beberapa contoh kategori adalah kesatuan, pluralitas, negasi, kemungkinan, dan kausalitas. Dalam pengalaman kita sehari-hari, kategori tidak pernah dipelajari tetapi selalu diandaikan. Tabel kategori terdapat dalam Kant, Immanuel. Critique of Pure Reason. Terj. Paul Guyer dan Allen W. Wood. Cambridge UP: 1998, 212 (B106). Lihat juga Longuenesse, Béatrice. "Kant on a priori concepts: The Metaphysical Deduction of the Categories", dalam The Cambridge Companion to Kant and Modern Philosophy, ed. Paul Guyer. Cambridge UP: 2006, 129-168, khususnya 146ff..
} 
ada, sebagai dasar segala pengalaman. Benjamin, sebaliknya, beranggapan bahwa kategori-kategori itu membutuhkan suplementasi kategori dari bidang lain, misalnya, linguistik, psikologi, seni, sejarah, teologi, dan metafisika (p. 134). Benjamin menamakan keseluruhan konseptual ini "doktrin tataran-

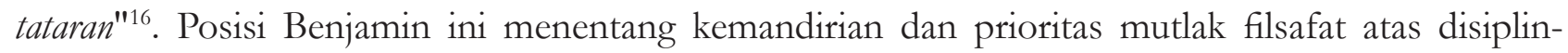
disiplin ilmiah yang lain. Sebaliknya, filsafat bersifat pasif: "Setiap filsafat harus berkembang dari suatu konfrontasi dengan suatu bidang pengalaman-suatu "ilmu" yang sudab dikonstitusikan terlebih dabulu-di luar filsafat itu" (p. 137-138) ${ }^{17}$. Benjamin lebih mementingkan pengalaman konkret daripada suatu sistem abstrak yang dianggap mendahului pengalaman itu.

Pengutamaan Benjamin akan pengalaman 'langsung' dilihat juga dari pengutamaan akan salah satu bentuk sejarah khusus, yaitu, anekdot. Anekdot adalah cerita kecil dari sejarah yang tidak resmi; istilahnya menurun dari anekdot dalam bahasa Yunani yang berarti "tidak diberikan, tidak diterbitkan" (p. 145). Sejarah 'resmi' cenderung mengutamakan naratif dan tokoh besar, dan sering juga disensor supaya integritas naratif itu serta reputasi tokoh itu dipertahankan. Anekdot, sebaliknya, seolaholah berasal 'dari bawah', dan demikian "membawakan hal-bal dekat dengan kita secara ruang" dan "secara kalender", yaitu, secara temporal; melalui anekdot, hal-hal "memasuki kehidupan kita" (p.155) ${ }^{18}$. Dengan kata lain, anekdot merupakan "tolok ukur manusiawi" (a human measure) untuk sejarah sendiri (p. 161). 'Sejarah anekdotal' tidak meniadakan pemikiran akan sejarah pada skala besar, tetapi cara kita memikirkan sejarah tetap diubah: Benjamin mengemukakan (dan sebenarnya, menurut Lehman, eksperimen pikiran yang serupa telah dilontarkan oleh Nietzsche dan Dilthey) bahwa kita bisa memikirkan rentang selama kurang-lebih 2000 tahun yang lampau sejak zaman Yesus sebagai runtunan masa hidup 40 orang yang semuanya hidup selama 50 tahun (p.146).

Theodor Adorno sempat mengkritik Benjamin ketika dia menggunakan anekdot; menurut Adorno, metode Benjamin sekedar menunjukkan secara pragmatis (pragmatic pointing) melalui presentasinya atas anekdot dan tidak melakukan interpretasi secara teoretis (p.157). Lehman membalas Adorno atas nama Benjamin dengan mengingatkan bahwa anekdot tidak sama dengan 'fakta empiris'; presentasi atas anekdot sudah merupakan representasi dan juga konstruksi atas suatu kontra-sejarah (p.160f.). Lebih jauh lagi, dalam suatu gestur yang menyejajarkan Benjamin dengan Eliot, Lehman mengemukakan bahwa anekdot merupakan suatu genre sastra (literary genre) yang melaluinya konsepsi baru Benjamin atas sejarah dapat dipahami (p. 161). Akhirnya, bagi Benjamin, Kehidupan, dalam bentuknya yang konkret dan partikular, adalah "otot yang cukup kuat sehingga keseluruban waktu historis dapat ditarik olebnya" (p. 170) ${ }^{19}$.

Selain dari kemungkinan konstruksi atas sejarah melalui anekdot di atas, Benjamin juga mempunyai suatu kemungkinan akan destruksinya, melalui alegori. Benjamin meneorikan alegori secara umum, tetapi dia lebih terkenal untuk salah satu alegori khusus: malaikat sejarah. Benjamin mendapatkan gambaran malaikat sejarah dalam sebuah lukisan Paul Klee yang berjudul Angelus Novus. Benjamin mendeskripsikannya sebagai berikut:

Matanya membeliak, mulutnya terbuka, sayapnya terbentang ... Mukanya terarah kepada masa lampau. Sementara kita melibat suatu runtunan peristiwa, dia melihat satu malapetaka tunggal, yang terus-menerus menumpuk.kan rongsokan di atas rongsokan dan melemparkan semuanya di depan kakinya. Malaikat ingin tinggal di sana, membangunkan mereka yang mati, dan memenubi apa yang sudah remuk. Tetapi badai meniup dari surga dan menangkap sayapnya ... badai ini mendorongnya secara tak terelakkan ke masa depan yang dia belakangi, sementara tumpukan rongsokan di hadapannya menjulang bingga ke langit. Apa yang kita namakan kemajuan adalab badai ini ${ }^{20}$ (p. 171).

\footnotetext{
16 (Lebre von den Ordungen; doctrine of orders)

17 "Every philosophy must develop out of a confrontation with a domain of experience-a preconstituted "science"-external to it".

18 "brings things near to us spatially"...." calendrically"....."enter our life".

19 "a muscle strong enough to contract the whole of historical time".

${ }^{20}$ His eyes are wide, his mouth is open, his wings are spread ... His face is turned toward the past. Where a chain of events appears before us, he sees one single catastrophe ... which keeps piling wreckage upon wreckage and hurls it at his feet. The angel would like to stay, awaken the dead, and make whole what has been smashed. But a storm is blowing from
} 
Alegori malaikat sejarah melawan konsep apapun tentang kemajuan (progress) dalam sejarah. Perlawanan terhadap kemajuan adalah sekaligus perlawanan terhadap penurunan (decline) seperti ditemukan dalam tulisan Oswald Spengler (p. 177). Dengan menyangkal baik kemajuan maupun penurunan, Benjamin menolak pemaksaan akan suatu naratif kepada sejarah. Satu hal yang kurang jelas bagi saya adalah apakah anekdot/alegori sebenarnya merupakan pasangan konsep konstruktif/ destruktif dalam Benjamin: sesudah alegori malaikat sejarah meniadakan naratif dalam sejarah, apakah anekdotlah yang menggantikannya? Atau, sebaliknya, apakah kedua konsep ini merupakan momen-momen yang berbeda dalam pemikiran Benjamin yang tidak dapat disesuaikan? Pesimisme dalam gambaran malaikat sejarah agak bertolak-belakang dengan suatu pembangunan yang akan menyusul sesudah pelewatannya.

Dalam suatu penutup yang singkat, Lehman mengemukakan kesamaan di antara Eliot dan Benjamin sebagaimana dia telah membahas mereka. Dia menyimpulkan bahwa "halilintar" dalam The Waste Land dan "badai yang membawa malaikat sejarab" menunjukkan perbatasan representasi secara historis (the limits of historical representation) dan demikian suatu 'luar-teks' yang pada dirinya dikonstruksi secara tekstual (p. 192). Namun, Lehman tidak ingin dianggap sebagai pemikir pascastrukturalis yang mereduksi segala-galanya menjadi bahasa. Sebaliknya, dia menekankan bahwa sejarah harus dipandang secara ganda, sebagai, baik merepresentasikan maupun direpresentasikan (p. 192). Dalam kajian Lehman, kegandaan itu dilihat dari penolakan atas historisisme baik dalam pembacaannya atas Eliot dan Benjamin sebagai tokoh dalam sejarah maupun dalam pembacaannya atas sejarah sebagaimana terdapat dan dikonstruksi di dalam dan melalui tulisan mereka. Menuju penutup resensi ini, saya ingin melontarkan dua pertanyaan kepada Lehman. Pertama: di kajian ini, Eliot dianggap gagal dalam menyatukan waktu historis dan waktu mitis dalam The Waste Land. Apakah kegagalan itu merupakan kegagalan niscaya? Apabila kita menganggap ranah mitos sebagai ranah yang kosong peristiwa dan tanpa naratif, sepertinya membahasakan mitos itu selalu akan merupakan suatu mediasi atau historisasi, karena bahasa bersifat naratif secara inheren. Apakah kita harus menerima ketidakmemadaian ini dan tetap memosisikan ranah mitos sebagai suatu 'yang lain mutlak' yang hanya bisa didekati secara tekstual tetapi tidak bakal dicapai? Apakah barangkali ada potensi dalam seni-seni non-verbal untuk lebih mendekati mitos?

Kedua, mengenai anekdot/alegori di atas, Lehman jelas-jelas menolak pembacaan historisis atas 'karir' penulisan Eliot dan Benjamin. Namun, bukankah pembacaan yang dilakukan oleh Lehman sendiri dalam kajian ini atas kedua pemikir tersebut tidak bebas dari asumsi naratif tertentu? Baik Eliot maupun Benjamin dibaca secara berurutan yang bermula dengan karya-karya awal lalu menelusuri gagasan-gagasan tertentu yang terdapat di sana sebagaimana dikembangkan dalam karya-karya 'dewasa'. Maksud pertanyaan ini bukan untuk menyindir Lehman melainkan menunjukkan suatu perbatasan terkait berapa jauh kita bisa mengikuti Benjamin dalam menolak sama sekali adanya naratif dalam sejarah. Tanpa naratif, bukankah yang ada hanyalah seruntunan peristiwa, dan bukankah setiap hubungan yang kita jalin di antara peristiwa-peristiwa merupakan suatu naratif dasar? Lebih jauh lagi, bukankah suatu presentasi belaka atas dua peristiwa tanpa komentar akan mengajak pembaca untuk menemukan suatu naratif yang menghubungkan mereka, ataupun menyiratkan suatu pemahaman naratif pada pihak si penyaji? Mungkinkah apa yang dilawan Benjamin bukan segala naratif melainkan bentuk naratif tertentu yang dianggap menindas sejauh memaksa apa yang partikular ke dalam suatu totalitas, atau apakah setiap naratif pada skala yang cukup besar akan mendekati totalitas seperti itu? Pertanyaan-pertanyaan saya ini barangkali menuju ke luar lingkup perhatian kajian Lehman, dan sebaiknya dianggap sebagai pertanyaan yang dibuka oleh teksnya daripada kekurangan dalam teks itu.

Sebagai penutup, siapapun sarjana yang berminat dengan [pasca] modernisme/modernitas dan sejarah intelektual secara umum, dan Eliot dan Benjamin secara khusus, akan menemukan banyak hal yang mencerahkan dan menggairahkan dalam buku Lehman ini. 